\title{
Editorial: Operationalizing the Concepts of Resilience and Resistance for Managing Ecosystems and Species at Risk
}

\author{
Jeanne C. Chambers ${ }^{1 *}$, Craig R. Allen ${ }^{2,3}$ and Samuel A. Cushman ${ }^{4}$ \\ ${ }^{1}$ USDA Forest Service, Rocky Mountain Research Station, Reno, NV, United States, ${ }^{2}$ School of Natural Resources, \\ University of Nebraska-Lincoln, Lincoln, NE, United States, ${ }^{3}$ Center for Resilience in Agricultural Working Landscapes, \\ University of Nebraska-Lincoln, Lincoln, NE, United States, ${ }^{4}$ USDA Forest Service, Center for Landscape Science, Rocky \\ Mountain Research Station, Flagstaff, AZ, United States
}

Keywords: ecological resilience, natural resources management, restoration, conservation, prioritization

\section{OPEN ACCESS}

Edited and reviewed by: Peter Convey, British Antarctic Survey (BAS), United Kingdom

*Correspondence: Jeanne C. Chambers jeanne.chambers@usda.gov

Specialty section:

This article was submitted to Biogeography and Macroecology,

a section of the journal Frontiers in Ecology and Evolution

Received: 04 May 2020 Accepted: 13 May 2020

Published: 11 June 2020

Citation:

Chambers JC, Allen CR and Cushman SA (2020) Editorial: Operationalizing the Concepts of Resilience and Resistance for Managing Ecosystems and Species at Risk. Front. Ecol. Evol. 8:168. doi: 10.3389/fevo.2020.00168

\section{Editorial on the Research Topic}

Operationalizing the Concepts of Resilience and Resistance for Managing Ecosystems and Species at Risk

Ecological resilience is essential for maintaining ecosystem services in an era of rapid global change, but successful attempts to operationalize it for managing ecosystems at risk have been limited. Clear formulation and application of ecological resilience concepts can guide ecosystem management so that it enhances the capacity of ecosystems to resist and recover from disturbances and provides adaptive space for periods of ecological reorganization. As originally defined, ecological resilience measures the amount of perturbation required to change an ecosystem from one set of processes and structures to a different set of processes and structures, or the amount of disturbance that a system can withstand before it shifts into a new regime or alternative stable state (Holling, 1973). In applied ecology, ecological resilience is increasingly used to evaluate the capacity of ecosystems to absorb, persist, and adapt to inevitable and often unpredictable change, and to use that information to determine the most effective management strategies (e.g., Chambers et al., 2014; Curtin and Parker, 2014; Pope et al., 2014; Seidl et al., 2016).

As the scale and magnitude of ecological change increases, operationalizing ecological resilience for ecosystem management becomes ever more important. To date, much of the literature on ecological resilience has focused on theory, definitions, and broad conceptualizations (e.g., Gunderson, 2000; Folke et al., 2004, 2010; Walker et al., 2004; Folke, 2006; Gunderson et al., 2010). Much of the more applied research has focused on the importance of species diversity and species functional attributes in affecting responses to stress and disturbance (e.g., Pope et al., 2014; Angeler and Allen, 2016; Baho et al., 2017; Roberts et al., 2018).

Recent, interdisciplinary research demonstrates that information on the relationships between an ecosystem's environmental characteristics (climate, topography, soils, and potential biota) and its response to stress and disturbance provides a viable mechanism for assessing ecosystem resilience and relative risks (Chambers et al., 2014; Hessburg et al., 2016; Cushman et al., 2017; Kaszta et al., 2019). Approaches have been developed that enable application of resilience concepts at the scales needed for effective management of ecosystems experiencing progressive and deleterious change. For example, in the sagebrush biome of the western U.S. the concepts of resilience to fire and resistance to non-native invasive annual grasses have recently been used in an interagency framework to enhance conservation and restoration and help prevent listing of greater 
sage-grouse (Centrocercus urophasianus) under the Endangered Species Act (Chambers et al., 2017). In ecosystems around the globe, levels of ecological stress and disturbance are increasing while resources for natural resources management remain limited. Fully developing the capacity to operationalize the concept of ecological resilience can enable managers to prioritize the types and locations of management activities needed to optimize ecosystem conservation and restoration.

This Research Topic includes a series of articles that address key questions for operationalizing ecological resilience and describes applications of ecological resilience concepts and approaches in natural resources management. Examples are included from a variety of ecosystem types and spatial and temporal scales.

\section{WHAT IS THE BASIS FOR APPLYING THE CONCEPT OF ECOSYSTEM RESILIENCE TO CONSERVATION AND RESTORATION MANAGEMENT?}

A resilience-based approach to management can facilitate regional planning by guiding the allocation of management resources to where they will have optimal socioecological benefits. This type of approach requires a sound understanding of the environmental factors, ecosystem attributes and processes, and landscape components that influence ecological resilience of the focal system. Chambers et al. review and integrate resilience concepts to help inform natural resources management decisions for ecosystems and landscapes. They describe the six key components of a resilience-based approach, beginning with managing for adaptive capacity and selecting an appropriate spatial extent and grain. Additional components include developing an understanding of the factors influencing the general and ecological resilience of ecosystems and landscapes, the landscape context and spatial resilience, pattern and process interactions and their variability, and relationships among ecological and spatial resilience and the capacity to support habitats and species. They suggest that a spatially explicit approach that couples geospatial information on general and spatial resilience to disturbance with information on resources, habitats, or species provides the foundation for resilience-based management. A case study from the sagebrush biome is provided that is widely used by the management agencies.

\section{HOW CAN RESILIENCE TO DISTURBANCE BE EVALUATED AND QUANTIFIED AT THE SCALES NEED TO FULLY OPERATIONALIZE THE CONCEPT?}

Developing an understanding of ecological resilience and operationalizing resilience-based management has become more tractable with the rapid increase in models and decisionsupport tools from the field of landscape ecology. Cushman and McGarigal present metrics and describe a process for using geospatial data, landscape pattern analysis, and spatially dynamic simulation modeling to evaluate ecological resilience at scales relevant for management. The dynamic equilibria of species abundances, community structure, and landscape patterns that are produced under a given combination of abiotic conditions, such as topography, soils, and climate, can form a foundation to define desired conditions and measure resistance and resilience. The degree of forcing required to push a system from this dynamic range is a measure of resistance, and the rate of return to the dynamic range after the perturbation is a measure of the resilience and recovery of the system. The authors describe tools that are useful in defining the dynamic range of an ecosystem under natural regulation and measuring the forcing required to drive departure and the rate of recovery, including simulation models, landscape pattern analyses, and multivariate trajectory analysis.

Uden et al. provide a new approach that uses spatial imaging-based screening to detect ecological regime shifts (i.e., vegetation state transitions) that are known to be detrimental to human well-being and ecosystem service delivery. They use a landcover dataset and a freely available, cloud-based, geospatial computing platform to screen for spatial signals of three common vegetation transitions in western USA rangelands: (1) erosion and desertification; (2) woody encroachment; and (3) annual non-native grass invasion. A series of locations that differ in ecological complexity and geographic extent are used to ask: (1) Which regime shift is expected or of greatest concern? (2) Can we detect a signal associated with the expected regime shift? (3) If detected, is the signal transient or persistent over time? (4) If detected and persistent, is the transition signal stationary or non-stationary over time? (5) What other signals do we detect? The approach enables managers to use spatial imaging to verify the occurrence of alternative vegetation regimes and track the type and magnitude of regime shift signals for more targeted evaluation (e.g., inventory and monitoring) and treatment of regime shifts.

Assessing landscape patterns in ecological resilience to climate vulnerability, disturbance and invasive species requires appropriate metrics of relevant environmental conditions. In dryland systems of western North America, soil temperature and moisture regimes identified in the National Soil Survey provide integrative indicators of long-term site aridity and have been widely used to evaluate resilience to disturbance and resistance to non-native invasive plant species. Bradford et al. used a processbased, ecosystem water balance model to characterize current and future patterns in soil temperature and moisture conditions in these drylands and evaluate the impact of changes in these conditions on estimation of resilience and resistance. Results indicate widespread geographic shifts in the distribution of soil temperature and moisture regimes, but inconsistencies in the direction of change for certain regimes. The use of ecologically relevant soil water balance metrics as indicators of ecological resilience and resistance may enhance the ability to project change as the climate warms.

Model study systems and organisms can be used to increase our understanding of patterns and processes of various aspects of regime dynamics at tractable time scales. Angeler et al. posit that ecological systems can manifest in and change between 
alternative regimes. They used discontinuity analysis to assess resilience attributes of spring and summer phytoplankton blooms based on a cross-scale resilience model and demonstrated that phytoplankton can be suitable models for assessing the intricacies of regimes and regime changes.

\section{HOW HAVE RESILIENCE CONCEPTS BEEN USED TO INFORM ECOSYSTEM CONSERVATION AND RESTORATION AT OPERATIONAL SCALES?}

Understanding ecosystem properties that reinforce ecological resilience and resistance in managed ecosystems can provide the basis for helping landscapes, species, and human communities adapt to changing conditions while maintaining core ecosystem processes and services. Hessburg et al. review the historical properties of western North American forests that reinforced resilience and resistance and show how multi-level landscape resilience, feedbacks within and among levels, and ecological conditions have changed under climatic and management influences. They discuss forest resilience and resistance to disturbances and the role of changes in regional climate and fire regimes in episodically reorganizing both plant and animal biogeography. They suggest that managing for resilient forests strongly depends on scale and human social values and requires embracing ongoing disturbances, anticipating effects of climatic changes, and supporting shifting patchworks of forest and non-forest.

Chambers et al. present new, spatially explicit approaches and decision-support tools that enable managers to better understand resilience to fire and resistance to non-native invasive annual grasses in dryland ecosystems and make more informed decisions. They review the abiotic and biotic factors that influence fire regimes, resilience to fire, resistance to non-native invasive annual grasses, and thus invasive grass-fire cycles, in global arid and semi-arid shrublands and woodlands. The Cold Deserts, Mediterranean Ecoregion, and Warm Deserts of North America are used as model systems to describe how and why resilience to disturbance and resistance to non-native invasive annuals differ over large landscapes. The Cold Deserts are used to illustrate an approach and decision-support tools for prioritizing areas on the landscape for management actions to prevent development of invasive grass-fire cycles and protect high value resources and habitats.

Ricca and Coates suggest that higher trophic-level fauna need to be included in tools to operationalize ecological resilience concepts because of spatiotemporal lags between slower reorganization of plant and soil processes and faster behavioral and demographic responses of fauna following disturbances. They provide multi-scale examples of decisionsupport tools for management and restoration actions in sagebrush ecosystems that evaluate ecological resilience based on variation in soil climate regimes through new lenses of habitat selection and population performance responses of an at-risk obligate species, the greater sage-grouse (Centrocercus urophasianus). They propose a targeted, operational approach to manage resilience that uses quantifiable metrics to limit spatiotemporal mismatches in restoration actions due to differences in sagebrush ecosystem recovery processes and sagegrouse population dynamics and identifies both active and passive management treatments across space and time.

\section{HOW CAN ECOLOGICAL RESILIENCE APPROACHES BE USED TO HELP ECOSYSTEMS AND THE COMMUNITIES THAT DEPEND ON THEM ADAPT TO INEVITABLE CHANGE?}

Management approaches based on ecological resilience can help communities prepare for, absorb, and adapt to change, but to be effective they must address the socioecological complexity of human-ecosystem interactions. Law can play an important role in promoting the resilience of ecosystems and communities to environmental change. Garmestani et al. suggest that as the climate warms and sea level rises, most coastal nations will need to transition to approaches based on ecological resilience and the law will be critical in facilitating this transition. They compare laws governing coastal zone management in Australia, Finland, and the Netherlands, and demonstrate that countries can adopt coastal zone management techniques that integrate social-ecological resilience. Importantly, they suggest that lawand-resilience research is needed to identify critical variables or sets of variables associated with countries' decisions to adopt laws designed to promote social-ecological resilience and mechanisms that allow for a smoother transition to this approach.

Using resilience concepts to characterize systems, and the social and ecological processes affecting them, is a way to integrate resilience into better management decisions. However, assessments of resilience are often challenging in complex socioecological systems facing unpredictable and unavoidable change. Lam et al. synthesize progress on the measurement of resilience on coral reefs and identify several novel, additional concepts that may have utility. Seven broad approaches are described under the three principle concepts of (1) ecological resilience (ecological resilience, precariousness and current attractor), (2) engineering resilience (short-term recovery rate and long-term reef performance), and (3) vulnerability (absolute and relative vulnerability, respectively). They evaluate both the strengths and limitations of each approach and their capacity to answer common management questions.

Camp et al. propose a framework based on inland recreational fisheries that allows resilience concepts to be better incorporated into management. The components are (1) recognizing how constraints and management objectives focus on desired or undesired systems; (2) evaluating how both social and ecological forces enforce or erode the desired or undesired system state; (3) identifying the resilience-stage cycles a system state may undergo; and (4) determining broad management strategies given the system state and resilience stage. They evaluate different system state and resilience stages and derive five management strategies: (1) adopt a different management preference or focus; (2) change stakeholder attitudes or behaviors 
via stakeholder outreach; (3) engage in biological intervention; (4) engage in fishery intervention; and (5) adopt landscape management approaches focusing on achieving different systems in different waters.

Kurth et al. emphasize that in coastal systems, aligning engineering, and ecological objectives can deliver a wide range of benefits. However, it is necessary to assess how ecosystembased approaches contribute to the resilience of coastal systems. They have developed and demonstrated an assessment rubric for Engineering With Nature ${ }^{\circledR}$ projects and they discuss its limitations and ways forward.

The papers in this Research Topic illustrate how ongoing work to operationalize ecological resilience concepts is improving strategic, multi-scale approaches for managing ongoing change to global ecological systems. Increased understanding of the ability of focal systems to maintain fundamental structures, processes, and functioning in the face of disturbances and stressors is being used to identify the relative ecological resilience

\section{REFERENCES}

Angeler, D. G., and Allen, C. R. (2016). Quantifying resilience. J. Appl. Ecol. 53, 617-624. doi: 10.1111/1365-2664.12649

Baho, D. L., Allen, C. R., Garmestani, A. S., Fried-Petersen, H. B., Renes, S. E., Gunderson, L., et al. (2017). A quantitative framework for assessing ecological resilience. Ecol. Soc. 22:17. doi: 10.5751/ES-09427220317

Chambers, J. C., Bradley, B. A., Brown, C. S., D’Antonio, C., Germino, M. J., Grace, J. B., et al. (2014). Resilience to stress and disturbance, and resistance to Bromus tectorum L. invasion in the cold desert shrublands of western North America. Ecosystems 7, 360-375. doi: 10.1007/s10021-0139725-5

Chambers, J. C., Maestas, J. D., Pyke, D. A., Boyd, C., Pellant, M., and Wuenschel, A. (2017). Using resilience and resistance concepts to manage persistent threats to sagebrush ecosystems and Greater sage-grouse. Rangeland Ecol. Manage. 70, 149-164. doi: 10.1016/j.rama.2016.08.005

Curtin, C. G., and Parker, J. P. (2014). Foundations of resilience thinking. Conserv. Biol. 28, 912-923. doi: 10.1111/cobi.12321

Cushman, S. A., Macdonald, E. A., Landguth, E. L., Malhi, Y., and Macdonald, D. W. (2017). Multiple-scale prediction of forest loss risk across Borneo. Landscape Ecol. 32, 1581-1598. doi: 10.1007/s10980-0170520-0

Folke, C. (2006). Resilience: the emergence of a perspective for socialecological systems analysis. Glob. Environ. Chang. 16, 253-267. doi: 10.1016/j.gloenvcha.2006.04.002

Folke, C., Carpenter, S. R., Walker, B., Scheffer, M., Chapin, T., and Rockström, J. (2010). Resilience thinking: integrating resilience, adaptability and transformability. Ecol. Soc. 15:20. Available online at: http://www. ecologyandsociety.org/vol15/iss4/art20/

Folke, C., Carpenter, S. R., Walker, B., Scheffer, M., Elmqvist, T., Gunderson, L., et al. (2004). Regime shifts, resilience, and biodiversity in ecosystem management. Annu. Rev. Ecol. Syst. 35, 557-581. doi: 10.1146/annurev.ecolsys.35.021103.105711

Gunderson, L. H. (2000). Ecological resilience - in theory and application. Ann. Rev. Ecol. Syst. 31, 425-439. doi: 10.1146/annurev.ecolsys.31.1.425 of ecosystems and impending transitions to alternative states. New geospatial data, tools, and models are allowing assessments of resilience from broad to local scales that can be used to target both restoration and conservation activities, and to determine the most appropriate management strategies. And approaches that explicitly address the socioecological complexities and multiscaled structure in systems show great promise in helping ecosystems and the communities that depend on them adapt to ongoing change. Clearly, resilience-based management in the Anthropocene will require new or stronger laws, policies, or guidelines. To ensure that resilience-based approaches to management are developed and applied to conserve and restore ecosystems effective collaboration among managers, scientists, and communities is a requisite.

\section{AUTHOR CONTRIBUTIONS}

JC, CA, and SC wrote and edited the article.

Gunderson, L. H., Allen, C. R., and Holling, C. S. (2010). Foundations of Ecological Resilience. New York, NY: Island Press.

Hessburg, P. F., Spies, T. A., Perry, D. A., Skinner, C. N., Taylor, A. H., Brown, P. M., et al. (2016). Tamm review: management of mixed-severity fire regime forests in Oregon, Washington, and Northern California. Forest Ecol. Manag. 366, 221-250. doi: 10.1016/j.foreco.2016.01.034

Holling, C. S. (1973). Resilience and stability of ecological systems. Annu. Rev. Ecol. Syst. 4, 1-23. doi: 10.1146/annurev.es.04.110173.000245

Kaszta, Z., Cushman, S. A., Hearn, A. J., Burnham, D., Macdonald, E. A., and Macdonald, D. W. (2019). Integrating Sunda clouded leopard conservation into development and restoration planning in Sabah. Biol. Conserv. 235, 63-76. doi: 10.1016/j.biocon.2019.04.001

Pope, K. L., Allen, C. R., and Angeler, D. G. (2014). Fishing for resilience. Am. Fish. Soc. 143, 467-478. doi: 10.1080/00028487.2014.880735

Roberts, C. P., Twidwell, D., Burnett, J. L., Donovan, V. M., Wonkka, C. L., Bielski, C. L., et al. (2018). Early warnings for state transitions. Rangeland Ecol. Manage. 71, 659-670. doi: 10.1016/j.rama.2018.04.012

Seidl, R., Spies, T. A., Peterson, D. L., Stephens, S. L., and Hick, J. A. (2016). Searching for resilience: addressing the impacts of changing disturbance regimes on forest ecosystem services. J. Appl. Ecol. 53, 120-129. doi: 10.1111/1365-2664.12511

Walker, B., Holling, C. S., Carpenter, S. R., and Kinzig, A. (2004). Resilience, adaptability and transformability in social-ecological systems. Ecol. Soc. 9:5. Available online at: http://www.ecologyandsociety.org/vol9/iss2/art5/

Conflict of Interest: The authors declare that the research was conducted in the absence of any commercial or financial relationships that could be construed as a potential conflict of interest.

Copyright $\odot 2020$ Chambers, Allen and Cushman. This is an open-access article distributed under the terms of the Creative Commons Attribution License (CC BY). The use, distribution or reproduction in other forums is permitted, provided the original author(s) and the copyright owner(s) are credited and that the original publication in this journal is cited, in accordance with accepted academic practice. No use, distribution or reproduction is permitted which does not comply with these terms. 